Article

\title{
Sustainability Life Cycle Cost Analysis of Roof Waterproofing Methods Considering $\mathrm{LCCO}_{2}$
}

\section{Sangyong Kim ${ }^{1}$, Gwang-Hee $\mathrm{Kim}^{2}{ }^{2 *}$ and Young-Do Lee ${ }^{3}$}

1 School of Construction Management and Engineering, University of Reading, Whiteknights PO Box 219, Reading RG6 6AW, UK; E-Mail: rd026992@reading.ac.uk

2 Department of Plant/Architectural Engineering, Kyonggi University, Suwon-si, Gyeonggi-do 443-760, Korea

3 Department of Architecture and Civil Engineering, Kyungdong University, Gosung-Goon, Gwangwon-do 219-705, Korea; E-Mail: lyd@k1.ac.kr

* Author to whom correspondence should be addressed; E-Mail: ghkim@kyonggi.ac.kr; Tel.: +82-31-249-9757; Fax: +82-31-244-6300.

Received: 27 September 2013; in revised form: 19 November 2013 / Accepted: 18 December 2013 / Published: 27 December 2013

\begin{abstract}
In a construction project, selection of an appropriate method in the planning/design stage is very important for ensuring effective project implementation and success. Many companies have adopted the life cycle cost (LCC) method, one of the methods for analyzing economic efficiency, for appropriate decision-making in the basic/detailed design stage by estimating overall costs and expenses generated over the entire project. This paper presents an LCC method for calculating the LCC of $\mathrm{CO}_{2}\left(\mathrm{LCCO}_{2}\right)$, based on materials committed during the lifecycle of a structure for each roof waterproofing method and adding this cost to the LCC for comparative analysis. Thus, this technique presents the LCC that includes the cost of $\mathrm{CO}_{2}$ emission. The results show that in terms of initial construction cost, asphalt waterproofing had the highest $\mathrm{CO}_{2}$ emission cost, followed by sheet waterproofing. $\mathrm{LCCO}_{2}$ did not greatly influence the initial construction cost and maintenance cost, as it is relatively smaller than the LCC. However, when the number of durable years was changed, the LCC showed some changes.
\end{abstract}

Keywords: life cycle cost; life cycle cost of $\mathrm{CO}_{2}$; roof waterproofing; $\mathrm{CO}_{2}$ emission 


\section{Introduction}

Construction projects have several standard stages, which the Project Management Institute categorizes as follows: initiation, planning, execution, and close [1]. In a construction project, these processes inevitably generate extra costs at every stage; therefore, a rigorous estimation procedure is necessary. In particular, it is crucial to adopt a suitable method for successful project delivery at process outset. In the construction industry, reasonable decisions are made by analyzing the economics of a project, using objectives and quantitative methods. This is done to ensure compliance with design regulations for safety, functionality, durability, and potential functions of the building by developing and adopting life cycle cost (LCC) and value engineering (VE) in their procedure. Simultaneously, project managers attempt to minimize extra expenses while meeting the structural and functional requirements of a project.

However, current economic analysis tools tend to have a limitation in terms of their applicable range as they merely focus on reducing direct costs for a project, such as labor, material, and site overhead cost. This implies that there is no consideration for the environment within these tools, which is a serious drawback. Among the harmful environmental effects of rapid industrial development, global warming is the most profound, and the solution to this problem demands extensive changes from the government, industry, and public [2]. This demand has resulted in the emergence of a paradigm globally, called 'sustainable development'. Sustainable development has become a common aspect in every activity owing to the environmental deterioration caused by aggressive human activity. This requires an active measure for considering the environmental impact caused by the construction industry in order to keep pace with global trends and respond to changes in domestic and foreign environmental policies. However, the LCC method, which is currently used in the initial stage of a project, considers only direct costs but not the environmental cost of $\mathrm{CO}_{2}$ management. Therefore, it is important to develop an integrated instrument that can assess the socio-environmental aspects of a project. For LCC estimation, common procedures from design to demolition and disposal are considered and the cost of each step is calculated. However, the proportion of waterproofing work in the overall construction is so small that it is difficult to estimate the associated amount of disposal work. Therefore, the purpose of this research is to propose an $\mathrm{LCC}$ calculation method that includes the cost of $\mathrm{CO}_{2}$ emission, $\mathrm{LCC}$, and $\mathrm{LCCO}_{2}$ during the demolition and disposal stages of a building. Sensitivity analysis related to alternatives and uncertain factors is omitted in this research.

Thus, this research proposes a new LCC method that includes $\mathrm{CO}_{2}$ emission cost by analyzing the entire LCC of different roof waterproofing methods by calculating the $\mathrm{LCC}$ of $\mathrm{CO}_{2}\left(\mathrm{LCCO}_{2}\right)$. Through conventional LCC analysis, it is possible to examine the economic feasibility of the new instrument, including the costs at the initial, operation and maintenance (O\&M), disposal, and demolition stages. Moreover, the new method can provide a reasonable logic for choosing a suitable construction method by considering the environmental impact of a project by including $\mathrm{LCCO}_{2}$ costs. Furthermore, this method can assist designers and engineers in systematic decision-making for selecting the most suitable alternative from economic and environmental viewpoints, which otherwise used to be based on their personal experience and knowledge. 


\section{Methodology}

In this research, LCC, which reflects the initial cost and the cost O\&M stages, such as labor, material, and disposal costs for replacement and maintenance, is calculated. The life cycle inventory (LCI) method, which is the data collection aspect of the LCA method, is used for tracking all flows in and out of the basic unit data of $\mathrm{CO}_{2}$ emissions of each material [3]. The calculated data is used for estimating total project cost, including the cost of $\mathrm{CO}_{2}$ emissions over the entire project life. It is ambiguous to stipulate standards for $\mathrm{CO}_{2}$ emission costs related to disposal, transport distance, loads, and the type of delivery vehicle [4]. Therefore, the research proceeds under the assumption that the $\mathrm{LCC}$ and $\mathrm{LCCO}_{2}$ are calculated at the demolition and disposal stage of a building, in compliance with the research purpose, which is to estimate the LCC including the $\mathrm{CO}_{2}$ emission cost.

The research procedure is as follows (see Figure 1): analyze the current research mainstream and determine limitations of past studies by reviewing literature on waterproofing methods that perform $\mathrm{LCC}$ and $\mathrm{LCCO}_{2}$ estimation; calculate the $\mathrm{LCCO}_{2}$ and $\mathrm{LCC}$ according to stages, such as material manufacturing and maintenance (including disposal costs), and; compare and analyze the LCC, which includes the $\mathrm{LCCO}_{2}$ of each roof waterproofing method.

Figure 1. Research procedure.

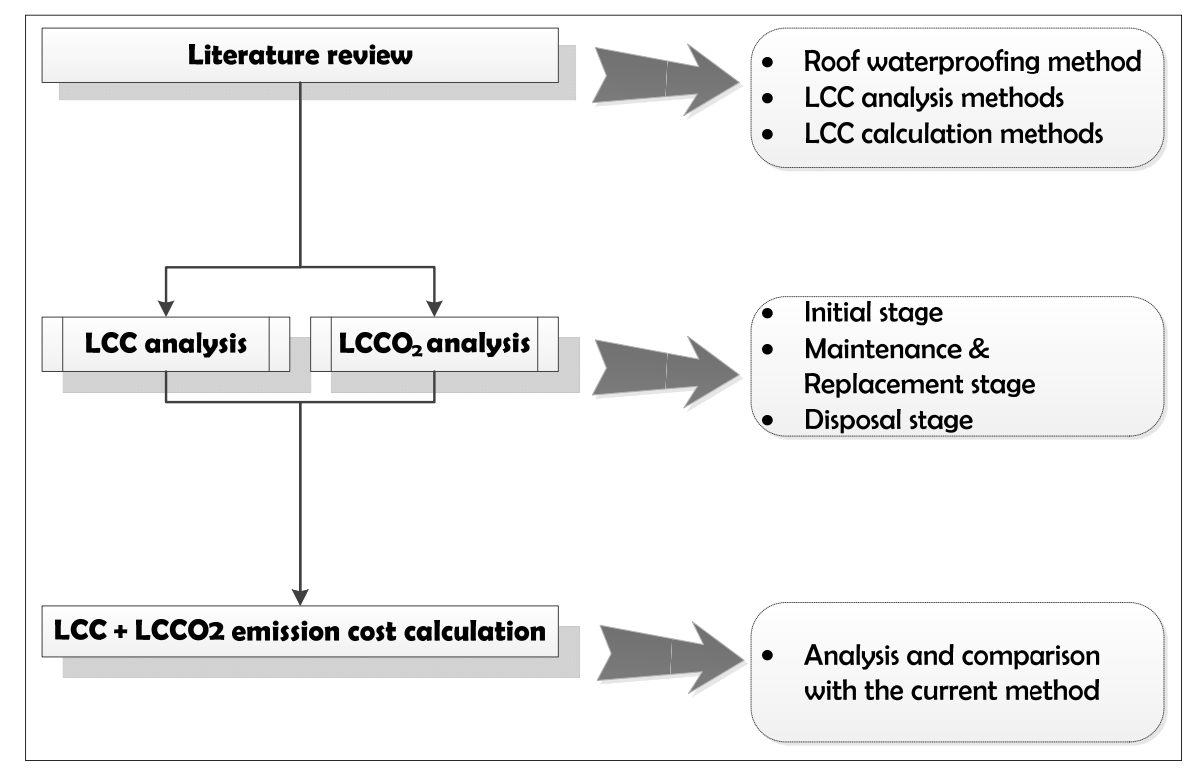

\section{Literature Review}

\subsection{Selection of Waterproofing Methods by LCC}

Conventionally, studies on waterproofing methods were focused on the assessment and improvement of the material functions by finding causes of defect and suggesting solutions to avoiding these causes. One study, conducted by Oh [5], suggested two solutions: to examine the liquid-applied membrane waterproofing method using recycled materials and the applicability of recycled materials to the liquid-applied membrane waterproofing. Kang [6] and An [7] analyzed the causes of waterproofing defects for developing desirable waterproofing design and methods. However, these studies tended to 
face several difficulties in terms of choosing a suitable waterproofing method at the planning and design stage.

Recently, there has been focus on applying various academic standards for finding and proposing objective and economic waterproofing methods at the initial planning and design stage. A representative study, conducted by $\mathrm{Oh}$ [8], suggested the capability assessment method for deciding the suitability of waterproofing methods by analyzing causes of defects in roof waterproofing. Kim [9], who built the cost categorizing system for individual waterproofing methods proposed an LCC analysis model for each waterproofing method for underground apartment structures by using previous study and examined the proposed model. A study conducted by Choi [10] is related to desirable economic models for estimating roof waterproofing costs, including initial, O\&M, and disposal costs. VE and LCC were adopted to devise a system for the analysis and application of VE procedures. A risk-based weighted LCC (RWLCC) cost estimate model [11] was also presented in that research.

\subsection{Cost Estimation of $\mathrm{CO}_{2}$ Emission}

Several studies have attempted to devise a method for quantifying $\mathrm{CO}_{2}$ emission and energy consumption of a certain building material, and subsequent conversion of the result into actual cost. Moreover, a number of studies have been conducted on constructing a database for calculating the $\mathrm{CO}_{2}$ emission unit price using LCA. Estimation using an accumulate method and an industrial relation table was introduced by Lee [12], and the actual quantity was estimated using input-output tables 1990 . The database of energy consumption and the basic unit price of $\mathrm{CO}_{2}$ emission was built using 1995, input-output tables of 2000 for developing unit price data and a program for assessing the overall LCA process by the department of construction. Kim [13,14] and Lee [15] proposed a model for estimating energy consumption and the $\mathrm{CO}_{2}$ emission basic unit price. The amount of energy consumed by the main construction materials was calculated in terms of $\mathrm{CO}_{2}$ consumption units. Based on previous studies, $\mathrm{CO}_{2}$ emissions for internal wall and floor components were estimated and compared in a quantitative manner. In addition, the emission quantity for each component of a masonry wall was calculated, and a method for converting the cost of trading $\mathrm{CO}_{2}$ emission price was proposed by Lee et al. [16].

Previous studies have focused on evaluating the performance of waterproofing methods and improving the same by applying scientific methods at the initial planning stage to achieve objective decision-making. In particular, selection of a method for determining cost over the entire lifecycle using the LCC analysis method, which is an economic method, is being researched. Some studies have aimed to estimate the $\mathrm{CO}_{2}$ emission of each construction method for determining the environmental impact, but no distinctive integrated study on economic and environmental factors has been conducted thus far.

\section{LCC Estimation}

\subsection{Selection of Roof Waterproofing Method}

As the function and capability of a building vary, the importance of proper waterproofing for each building is emphasized. The waterproofing methods preferred for new buildings and for refurbishment are shown in Figure 2. Subsequently, the top three preferred waterproofing methods were chosen for comparison in our research: asphalt, sheet, and membrane waterproofing. 
Figure 2. Waterproofing method preference [7].

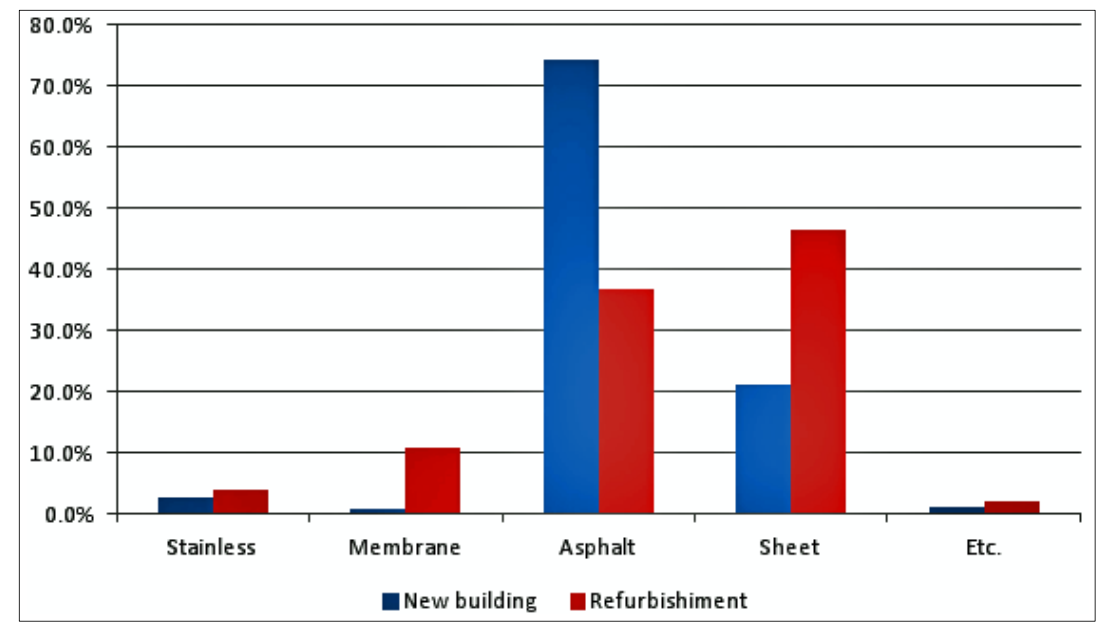

In order to calculate $\mathrm{LCCO}_{2}$ and $\mathrm{LCC}$ by each waterproofing method, the components of three waterproofing methods are identified in Table 1 according to the itemized unit cost and a standard of estimate.

Table 1. Components of roof waterproofing system.

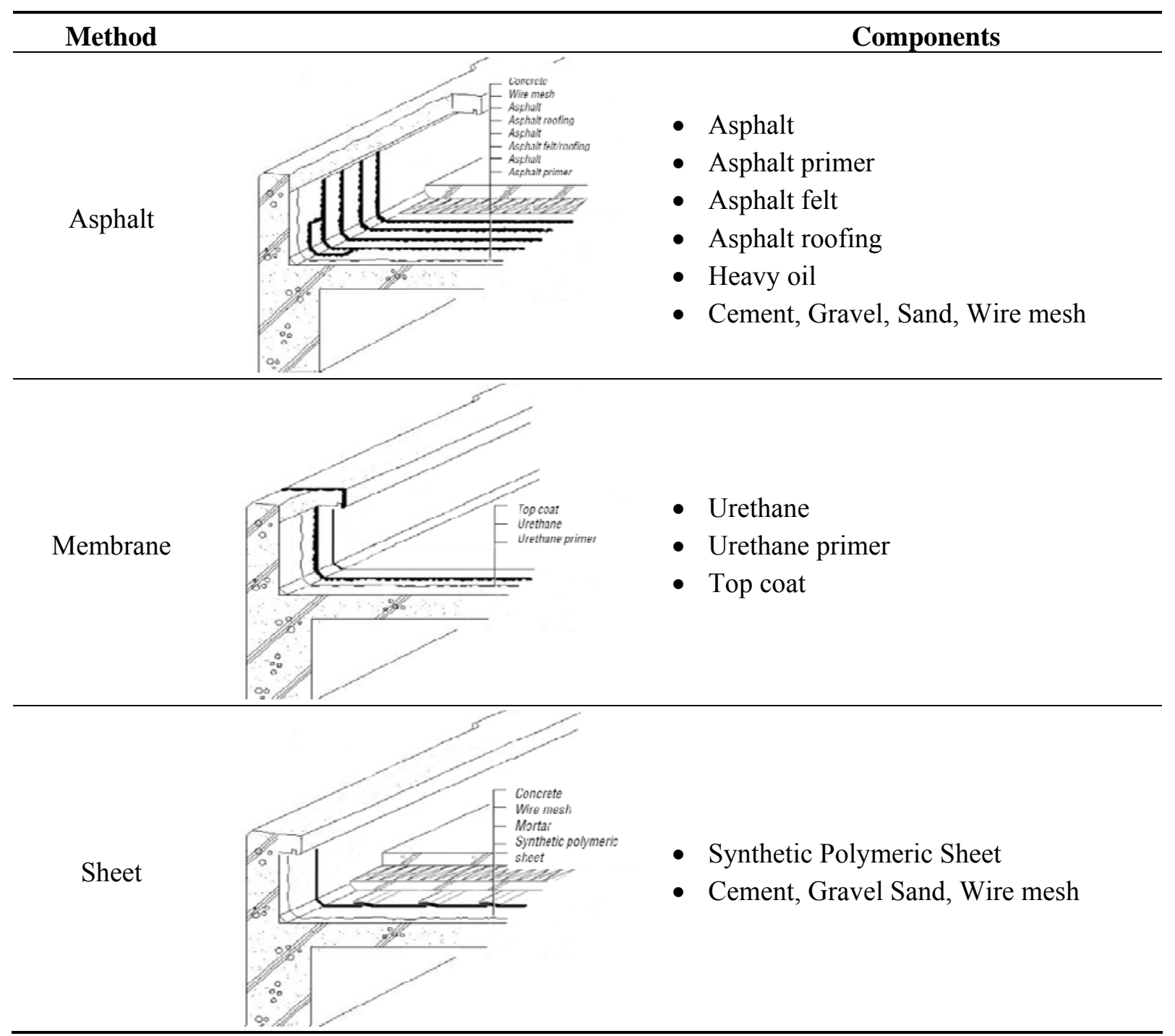




\subsection{LCC Assessment Method}

In LCC analysis, cost factors identified using cost breakdown structure (CBS) are generated continuously over the lifecycle of a building. To maintain the equivalent value of the cost, which is created on a different timeline, it is necessary to convert all cost factors in CBS into the same value for accurate LCC calculations. In addition, the time reference point for converting different values should be decided in advance. This is because the LCC method can be divided into three sub-methods, based on the reference point: the present, annual value method, and future value method. Generally, the present and future value methods are useful for comparing alternatives with equal calculation periods, whereas the annual value method is useful when the periods are not identical. These three methods are correlated but the present and annual value methods are generally adopted for LCC calculations.

\subsection{Repair Period and Repair Rate}

In this study, the waterproofing time and repair rate suggested in the 'Housing Act Enforcement Regulations in Korea' are the basis for calculating the LCC, and the detailed numbers are listed in Table 2.

Table 2. Repair period and ration.

\begin{tabular}{lccc}
\hline & Area & Period & Ratio (\%) \\
\hline \multirow{2}{*}{ Asphalt waterproofing } & Partial & 8 & 10 \\
\cline { 2 - 4 } & Full & 25 & 100 \\
\hline \multirow{2}{*}{ Membrane waterproofing } & Partial & 5 & 10 \\
\cline { 2 - 4 } & Full & 15 & 100 \\
\hline \multirow{2}{*}{ Sheet waterproofing } & Partial & 8 & 20 \\
\cline { 2 - 4 } & Full & 20 & 100 \\
\hline
\end{tabular}

\subsection{Analysis Period}

Analysis period is a crucial variable that can influence the LCC calculation; therefore, sufficient rigor must be exercised for determining this period [17,18]. The analysis period is not merely a comparison process for input costs over the entire life but the critical point that decides the break-even point of a project. Therefore, the period should be calculated by considering building attributes and purpose. There is a broad consensus that the concept of durable years is associated with a lifecycle accounting approach to building design, construction, and management. Each subsystem is assigned an optimum expected useful life and installed accordingly. For waterproofing, its lifetime is equal to the lifetime of a building as the waterproofing function is expected to be performed over the lifecycle of the building, as shown in Table 3 [19].

Table 3. A durable period of a build.

\begin{tabular}{ll}
\hline \multicolumn{1}{c}{ Period } & \multicolumn{1}{c}{ Types of asset } \\
\hline 5 years (4-6 years) & Vehicle and transport. Equipment, instrument and tool \\
\hline 12 years $(9-15$ years $)$ & Ship and aircraft \\
\hline 20 years (15-25 years) & $\begin{array}{l}\text { All structure building including a brick building, block building, } \\
\text { concrete-ramen building, wooden building, wooden-mortar building }\end{array}$ \\
\hline 40 years (30-50 years) $)$ & $\begin{array}{l}\text { Steel frame, Steel-concrete structure, masonry stone structure, } \\
\text { all beam structure building }\end{array}$ \\
\hline
\end{tabular}


There is no certain durable period in LCC estimations, but it ranges between 30 and 50 years. In this research, 45 years is considered as the durable period for the analysis of a build-transfer-lease project.

\subsection{Discount Rate}

As mentioned previously, future cost has a different value than the current value, even for identical face values. To resolve this difference, a discount rate, which is the interest rate used in discounted cash flow analysis for determining the present value of a future cash flows, is applied. The rate can be classified as a nominal discount rate, which does not consider the inflation rate, and the real discount rate, which includes inflation. In the LCC analysis, the real discount rate is usually adopted as the discount rate [20]. Therefore, the real discount rate is applied according to Equation (1).

$$
\left(1+i_{n}\right)=\left(1+i_{r}\right) \times(1+f) \quad \therefore i_{r}=\frac{\left(1+i_{n}\right)}{(1+i)}-1
$$

where, $i_{r}$ : real discount rate, $i_{n}$ : nominal discount rate, $f$ : rate of inflation.

The interest rate of Korean banks and the CPI (Consumer Price Index) from national statistics are used for calculating the nominal discount rate and inflation rate, and the calculated real discount rate is shown in Table 4.

Table 4. Real discount rate.

\begin{tabular}{ccccc}
\hline Year & $\begin{array}{c}\text { Interest rate } \\
(\mathbf{\%})\end{array}$ & $\begin{array}{c}\text { Consumer Price Index } \\
(\mathbf{C P I}, \mathbf{Y 2 0 1 0}=\mathbf{1 0 0})\end{array}$ & $\begin{array}{c}\text { Inflation rate } \\
\mathbf{( \% )}\end{array}$ & $\begin{array}{c}\text { Real rate of } \\
\text { interest (\%) }\end{array}$ \\
\hline 1996 & 9.00 & 63.15 & 9.00 & 3.83 \\
1997 & 10.59 & 65.96 & 4.44 & 5.89 \\
1998 & 13.39 & 70.91 & 7.51 & 5.47 \\
1999 & 7.05 & 71.49 & 0.81 & 6.19 \\
2000 & 7.08 & 73.10 & 2.26 & 4.71 \\
2001 & 5.46 & 76.08 & 4.07 & 1.34 \\
2002 & 4.71 & 78.18 & 2.76 & 1.89 \\
2003 & 4.15 & 80.92 & 3.51 & 0.61 \\
2004 & 3.75 & 83.83 & 3.59 & 0.15 \\
2005 & 3.57 & 86.14 & 2.75 & 0.79 \\
2006 & 4.36 & 88.07 & 2.24 & 2.07 \\
2007 & 5.01 & 90.30 & 2.53 & 2.41 \\
2008 & 5.67 & 94.52 & 4.67 & 0.95 \\
2009 & 3.23 & 97.13 & 2.76 & 0.46 \\
2010 & 3.18 & 100.00 & 2.96 & 0.22 \\
2011 & 3.69 & 104.00 & 4.00 & -0.30 \\
\hline
\end{tabular}

\subsection{LCC Calculation}

The fundamental cost information for calculating the LCC of roof waterproofing construction can be divided into three categories: initial construction cost, O\&M cost, and disposal cost. To obtain relevant cost information, identified components of each construction method and a standard of estimation and itemized unit cost from 2009 are used for calculation. In general situations, the bill of 
quantity includes site overhead costs and general overhead costs. For objective comparison, these costs were excluded from this study.

The initial construction cost for each method was calculated using a standard of estimation and the itemized unit cost by process analysis. As a result, the initial costs of three methods are in the order of asphalt, membrane, and sheet waterproofing. O\&M cost or repair cost, in this case, is calculated based on the "Housing Act Enforcement Regulations". In the case of asphalt and membrane waterproofing, repair work is needed at the rate of $10 \%$, eight years after the initial work. Based on the repair rate, the rate of $10 \%$ for the total area is calculated considering the disposal of previous work and repair work for eight-layered asphalt waterproofing. The repair rate for sheet waterproofing work is assumed as $20 \%$ and is calculated in a manner that is identical for the former work. The "2008 Unit Price for Construction Waste by a Location in Korea" is applied for demolition and disposal work for a waterproofing layer and the repair cost for each method are presented in table. The outcomes of the cost calculations are given in Table 5. The result shows that sheet waterproofing accounts for the highest cost for single partial waterproofing repair, followed by asphalt and membrane waterproofing. Disposal cost is generated owing to the removal of the existing waterproofing layer. In order to calculate the disposal cost, the "2008 Unit Price for Construction Waste by a Location in Korea" standard is applied to all three study methods.

Table 5. Repair cost for a roof waterproofing system.

\begin{tabular}{|c|c|c|c|c|c|}
\hline System & Specification & Unit $\left(\mathrm{m}^{2}\right)$ & Material cost & Labor cost & Total \\
\hline \multirow{3}{*}{$\begin{array}{l}\text { Asphalt (Repair } \\
\text { period: } 8 \text { years, } 10 \% \text { ) }\end{array}$} & Major repair & 0.1 & 1338 & 3094 & 4432 \\
\hline & $\begin{array}{l}\text { Waterproof layer } \\
\text { demolition and disposal }\end{array}$ & 0.1 & & & 2439 \\
\hline & Sum & & & & 6871 \\
\hline \multirow{3}{*}{$\begin{array}{l}\text { Membrane (Repair } \\
\text { period: } 5 \text { years, } 10 \% \text { ) }\end{array}$} & Major repair & 0.1 & 2624 & 1530 & 4154 \\
\hline & $\begin{array}{l}\text { Waterproof layer } \\
\text { demolition and disposal }\end{array}$ & 0.1 & & & 2439 \\
\hline & Sum & & & & 6592 \\
\hline \multirow{3}{*}{$\begin{array}{l}\text { Sheet (Repair } \\
\text { period: } 8 \text { years, 20\%) }\end{array}$} & Major repair & 0.2 & 2322 & 4001 & 6323 \\
\hline & $\begin{array}{l}\text { Waterproof layer } \\
\text { demolition and disposal }\end{array}$ & 0.2 & & & 4877 \\
\hline & Sum & & & & $11,200.4$ \\
\hline
\end{tabular}

\section{5. $\mathrm{LCCO}_{2}$ Estimation}

Prior to the calculation of $\mathrm{CO}_{2}$ emission cost by roof waterproofing in the initial stage, the construction materials corresponding to the input-output tables, which categorize 404 items of industrial materials, should be classified. The waterproofing methods selected for this study are classified in Table 6 and the components of each method are listed. Based on this classification, material quantity per unit is calculated by referring to the itemized unit price and a standard of estimation. The estimated quantity of a material is multiplied with the $\mathrm{CO}_{2}$ emission basic unit ( $\mathrm{kg}-\mathrm{CO}_{2} /$ won) for arriving at the $\mathrm{CO}_{2}$ emission and emission cost. 
Table 6. Component classification of roof waterproofing system.

\begin{tabular}{|c|c|c|c|}
\hline System & Material & Unit & Quantity \\
\hline \multirow{9}{*}{ Asphalt } & Asphalt & $\mathrm{kg}$ & 7.1 \\
\hline & Asphalt primer & $\mathrm{L}$ & 0.4 \\
\hline & Asphalt felt & $\mathrm{m}^{2}$ & 1.1 \\
\hline & Asphalt roofing & $\mathrm{m}^{2}$ & 2.2 \\
\hline & Heavy oil & $\mathrm{L}$ & 0.8 \\
\hline & Cement & $\mathrm{kg}$ & 6.8 \\
\hline & Gravel & $\mathrm{kg}$ & 0.1913 \\
\hline & Sand & $\mathrm{m}^{3}$ & 0.0098 \\
\hline & Wire mesh & $\mathrm{kg}$ & 3.486 \\
\hline \multirow{7}{*}{ Membrane } & Urethane & $\mathrm{kg}$ & 3.9 \\
\hline & Urethane primer & $\mathrm{kg}$ & 0.3 \\
\hline & Coating material & $\mathrm{kg}$ & 0.3 \\
\hline & Cement & $\mathrm{kg}$ & 6.8 \\
\hline & Gravel & $\mathrm{kg}$ & 0.1913 \\
\hline & Sand & $\mathrm{m}^{3}$ & 0.0098 \\
\hline & Wire mesh & $\mathrm{kg}$ & 3.486 \\
\hline \multirow{5}{*}{ Sheet } & Synthetic & $\mathrm{m}^{2}$ & 1.2 \\
\hline & polymeric sheet & $\mathrm{kg}$ & 6.8 \\
\hline & cement & $\mathrm{kg}$ & 0.1913 \\
\hline & Gravel & $\mathrm{m}^{3}$ & 0.0098 \\
\hline & $\begin{array}{l}\text { Sand } \\
\text { Wire mesh }\end{array}$ & $\mathrm{kg}$ & 3.486 \\
\hline
\end{tabular}

\subsection{Selection of Environmental Load Database}

Construction materials in basic units are a prerequisite for constructing the database of the amount of energy consumed and $\mathrm{CO}_{2}$ emission, which is required for estimating the energy consumption and $\mathrm{CO}_{2}$ emission of the components and activities of roof waterproofing. To this end, the environment load basic unit database suggested by a previous Korea Institute of Construction Technology (2004) is adopted. In the previous study, detailed data on the energy consumption of construction materials and resources with basic units of $\mathrm{CO}_{2}$ emission using input-output tables was calculated. Based on the previous study, the materials and resources pertinent to each method are analyzed for calculating $\mathrm{CO}_{2}$ emissions involved in individual roof waterproofing according to the industrial categories in response to the input-output tables as suggested in Table 7.

Table 7. $\mathrm{CO}_{2}$ emission basic unit and energy consumption of materials and products.

\begin{tabular}{clcc}
\hline Code & \multicolumn{1}{c}{ Part name } & Material & $\begin{array}{c}\mathbf{C O}_{2} \mathbf{e m i s s i o n} \text { amount } \\
\left(\mathbf{t}-\mathbf{C O}_{2} / \mathbf{M w o n}\right)\end{array}$ \\
\hline 00390100 & Sand & Sand & 0.3538 \\
00390200 & Gravel & Gravel & 0.3538 \\
01440100 & Heavy oil & Heavy oil & 3.7367 \\
01920200 & Asphalt product & Asphalt & 1.7535 \\
01710100 & Wax and coating product & Coating material & 1.815 \\
\hline
\end{tabular}


Table 7. Cont.

\begin{tabular}{cllc}
\hline Code & \multicolumn{1}{c}{ Part name } & \multicolumn{1}{c}{ Material } & $\begin{array}{c}\mathbf{C O}_{2} \mathbf{e m i s s i o n} \text { amount } \\
\left(\mathbf{t}-\mathbf{C O}_{2} / \mathbf{M w o n}\right)\end{array}$ \\
\hline 01650301 & Thinner & Thinner & 1.602 \\
01850101 & Normal cement & Cement & 6.616 \\
01550100 & Synthetic rubber & Synthetic polymer sheet & 1.7407 \\
01670100 & Adhesive(industrial) & Primer & 1.382 \\
01650201 & Urethane product & Urethane & 1.602 \\
01920200 & Asphalt product & Asphalt primer & 1.7535 \\
01920200 & Asphalt product & Asphalt felt & 1.7535 \\
01920200 & Asphalt product & Asphalt roofing & 1.7535 \\
02210103 & Steel net & Wire mesh & 3.738 \\
\hline
\end{tabular}

\subsection{Application of $\mathrm{CO}_{2}$ Market Price}

The cost of $\mathrm{LCCO}_{2}$ emission can be estimated by multiplying the required material cost of a component with the $\mathrm{CO}_{2}$ emission basic units of identified major construction materials. The multiplied cost should be converted into the current market-traded $\mathrm{CO}_{2}$ emission price. As mentioned earlier, there are various markets for trading emission rights with the intention of controlling air pollution in developed countries. Among various markets, the price of the EU Allowance (EUA), which is traded in the EU Emission Trading Scheme (EU ETS), is adopted to calculate the $\mathrm{LCCO}_{2}$ and the average price of $\mathrm{CO}_{2}$ emission (from 2005 to 2009), as suggested by ECX, is applied. The average price is $19.73 \mathrm{EUR} /$ ton. In addition, the average Euro:Won exchange rate in 2009 is applied, which is the standard currency in the European Climate Exchange (ECX) as shown in Figure 3.

Figure 3. EU Allowance (EUA) price (2006-2009).

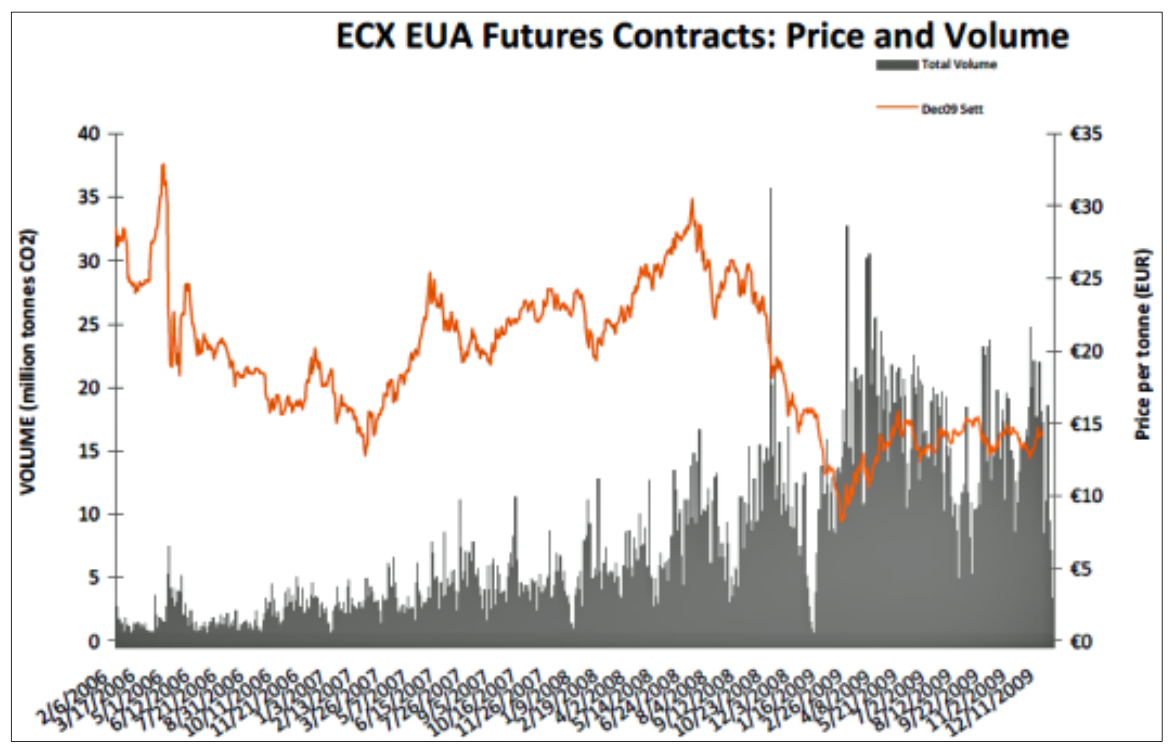

\section{3. $\mathrm{LCCO}_{2}$ Cost Calculation}

The $\mathrm{CO}_{2}$ emission volume can be calculated from the product of three variables: required material quantity, material unit cost, and $\mathrm{CO}_{2}$ emission basic unit. The calculated results are presented in Table 8. 
Table 8. $\mathrm{CO}_{2}$ emission volume $\left(\mathrm{m}^{2}\right)$.

\begin{tabular}{|c|c|c|c|c|c|c|}
\hline Systems & Material & Unit cost & Quantity & $\mathrm{CO}_{2}$ basic unit & $\mathrm{CO}_{2}$ emission volume & Sum \\
\hline \multirow{9}{*}{ Asphalt } & Asphalt primer & 1277 & 0.0005108 & 1.7535 & 0.0008957 & \multirow{9}{*}{0.0297637} \\
\hline & Blown asphalt & 730 & 0.0051830 & 0.861 & 0.0090884 & \\
\hline & Asphalt felt & 1666 & 0.0018326 & 1.7535 & 0.0032135 & \\
\hline & Asphalt roofing & 500 & 0.0011000 & 1.7535 & 0.0019289 & \\
\hline & Heavy oil & 654 & 0.0005326 & 3.7367 & 0.0019902 & \\
\hline & Cement & 79 & 0.0005372 & 6.616 & 0.0035541 & \\
\hline & Gravel & 12,500 & 0.0002391 & 0.3538 & 0.0000846 & \\
\hline & Sand & 12,500 & 0.0001225 & 0.3538 & 0.0000433 & \\
\hline & Wire mesh & 688 & 0.0023984 & 3.738 & 0.0089651 & \\
\hline \multirow{8}{*}{ Membrane } & Urethane & 4900 & 0.0005134 & 1.382 & 0.0306142 & \multirow{8}{*}{0.0487873} \\
\hline & Urethane primer & 4900 & 0.0191100 & 1.602 & 0.0026681 & \\
\hline & Coating material & 1277 & 0.0014700 & 1.815 & 0.0007095 & \\
\hline & Thinner & 3271 & 0.0013411 & 1.602 & 0.0021485 & \\
\hline & Cement & 79 & 0.0005372 & 6.616 & 0.0035541 & \\
\hline & Gravel & 12,500 & 0.0002391 & 0.3538 & 0.0000846 & \\
\hline & Sand & 12,500 & 0.0001225 & 0.3538 & 0.0000433 & \\
\hline & Wire mesh & 688 & 0.0023984 & 3.738 & 0.0089651 & \\
\hline \multirow{6}{*}{ Sheet } & $\begin{array}{l}\text { Synthetic } \\
\text { polymer sheet }\end{array}$ & 6000 & 0.0072000 & 1.7407 & 0.0125330 & \multirow{6}{*}{0.0258896} \\
\hline & Cement & 79 & 0.0005372 & 6.616 & 0.0035541 & \\
\hline & Gravel & 12,500 & 0.0002391 & 0.3538 & 0.0000846 & \\
\hline & Sand & 12,500 & 0.0001225 & 0.3538 & 0.0000433 & \\
\hline & Primer & 688 & 0.0005134 & 1.382 & 0.0089651 & \\
\hline & Wire mesh & 1277 & 0.0023984 & 3.738 & 0.0007095 & \\
\hline
\end{tabular}

Based on the calculated $\mathrm{CO}_{2}$ emission volume, $\mathrm{CO}_{2}$ emission cost is obtained by multiplying it with the average EUA price and the average currency price, as listed in Table 9. The $\mathrm{CO}_{2}$ emission cost of roof waterproofing in terms of required materials is in the following order: membrane waterproofing, asphalt waterproofing, and sheet waterproofing.

Table 9. Cost for $\mathrm{CO}_{2}$ emission at construction stage.

\begin{tabular}{lcccc}
\hline & $\begin{array}{c}\mathbf{C O}_{2} \text { emission } \\
\text { volume }\end{array}$ & $\begin{array}{c}\text { Average price of } \\
\text { EUAs (EUR/ton) }\end{array}$ & $\begin{array}{c}\text { Average exchange } \\
\text { currency }\end{array}$ & $\begin{array}{c}\mathbf{C O}_{2} \\
\text { emission cost }\end{array}$ \\
\hline Asphalt waterproofing & 0.0297637 & & & 1062.70 \\
Membrane waterproofing & 0.0487873 & 19.73 & 1809.65 & 1741.92 \\
Sheet waterproofing & 0.0258896 & & & 924.37 \\
\hline
\end{tabular}

Roof waterproofing maintenance work involves partial or complete demolition. Therefore, the equipment used for demolition and rework is input for roof waterproofing maintenance work. This input can be a factor in calculating the cost of roof waterproofing maintenance work. In the case of equipment, a breaker $\mathrm{CO}_{2}$ emission basic unit proposed by the Table 10 can be used for calculating the cost of demolition work as part of maintenance work. 
Table 10. $\mathrm{CO}_{2}$ emission cost for a waterproofing layer demolition.

\begin{tabular}{cccccc}
\hline Equipment & Unit $\left(\mathbf{m}^{2}\right)$ & $\begin{array}{c}\mathbf{C O}_{2} \text { basic unit } \\
\left(\mathbf{k g}-\mathbf{C C O}_{2} / \mathbf{m}^{2}\right)\end{array}$ & $\begin{array}{c}\text { Average price of } \\
\text { EUAs (EUR/ton) }\end{array}$ & $\begin{array}{c}\text { Average exchange } \\
\text { currency (year) }\end{array}$ & $\begin{array}{c}\text { Costs } \\
\left(\mathbf{W o n} / \mathbf{m}^{2}\right)\end{array}$ \\
\hline Breaker & 0.12 & 0.687 & 19.73 & 1809.65 & 2452.89 \\
\hline
\end{tabular}

The initial $\mathrm{CO}_{2}$ emission cost calculation method is used for materials, and the cost of a sample repair and replacement work is presented in Tables 11 and 12. The calculated results show that the membrane-waterproofing method requires the highest expense in maintenance stage, followed by asphalt and sheet waterproofing, as can be seen in Table 12.

Table 11. $\mathrm{CO}_{2}$ emission cost for repair.

\begin{tabular}{|c|c|c|c|c|c|}
\hline System & Specification & Unit $\left(\mathrm{m}^{2}\right)$ & Material cost & Labor cost & Total \\
\hline \multirow{3}{*}{$\begin{array}{c}\text { Asphalt } \\
\text { (Replacement period: } \\
25 \text { years, } 10 \% \text { ) }\end{array}$} & Partial repair & 0.1 & 106.27 & 0 & 106.27 \\
\hline & $\begin{array}{l}\text { Waterproof layer } \\
\text { demolition(breaker) }\end{array}$ & 0.1 & & & 245.29 \\
\hline & Sum & & & & 351.56 \\
\hline \multirow{3}{*}{$\begin{array}{c}\text { Membrane } \\
\text { (Replacement period: } \\
15 \text { years, } 10 \% \text { ) }\end{array}$} & Partial repair & 0.1 & 174.19 & 0 & 174.19 \\
\hline & $\begin{array}{l}\text { Waterproof layer } \\
\text { demolition(breaker) }\end{array}$ & 0.1 & & & 245.29 \\
\hline & Sum & & & & 419.48 \\
\hline \multirow{3}{*}{$\begin{array}{c}\text { Sheet } \\
\text { (Replacement period: } \\
20 \text { years, } 20 \% \text { ) }\end{array}$} & Partial repair & 0.2 & 184.87 & 0 & 184.87 \\
\hline & $\begin{array}{l}\text { Waterproof layer } \\
\text { demolition(breaker) }\end{array}$ & 0.2 & & & 409.58 \\
\hline & Sum & & & & 675.45 \\
\hline
\end{tabular}

Table 12. $\mathrm{CO}_{2}$ emission cost for replacement.

\begin{tabular}{|c|c|c|c|c|c|}
\hline System & Specification & Unit $\left(\mathrm{m}^{2}\right)$ & Material cost & Labor cost & Total \\
\hline \multirow{3}{*}{$\begin{array}{c}\text { Asphalt } \\
\text { (Replacement period: } \\
25 \text { years, } 10 \%)\end{array}$} & Partial replacement & 0.1 & 1062.70 & 0 & 1062.70 \\
\hline & $\begin{array}{l}\text { Waterproof layer } \\
\text { demolition(breaker) }\end{array}$ & 0.1 & & & 2452.89 \\
\hline & Sum & & & & 3515.59 \\
\hline \multirow{3}{*}{$\begin{array}{c}\text { Membrane } \\
\text { (Replacement period: } \\
15 \text { years, } 10 \% \text { ) }\end{array}$} & Partial replacement & 0.1 & 1741.92 & 0 & 1741.92 \\
\hline & $\begin{array}{l}\text { Waterproof layer } \\
\text { demolition(breaker) }\end{array}$ & 0.1 & & & 2452.89 \\
\hline & Sum & & & & 4194.81 \\
\hline \multirow{3}{*}{$\begin{array}{c}\text { Sheet } \\
\text { (Replacement period: } \\
20 \text { years, } 20 \% \text { ) }\end{array}$} & Partial replacement & 0.2 & 924.37 & 0 & 924.37 \\
\hline & $\begin{array}{l}\text { Waterproof layer } \\
\text { demolition(breaker) }\end{array}$ & 0.2 & & & 2452.89 \\
\hline & Sum & & & & 3377.27 \\
\hline
\end{tabular}

In addition, the cost of transporting debris to a landfill or temporary disposal site should be considered while calculating the $\mathrm{CO}_{2}$ emission cost of the demolition and disposal stage. However, owing to the very limited amount of construction waste from roof waterproofing, this cost can be expected to be a very small percentage of the total cost. In addition, because there is uncertainty in 
setting a standard for distance and vehicles for handling the waste, the cost of $\mathrm{CO}_{2}$ emission from transport in the demolition and disposal stage is not considered.

\section{LCC Comparison Including $\mathrm{LCCO}_{2}$}

\subsection{Initial Cost}

As suggested in Table 13, the initial construction cost excluding $\mathrm{CO}_{2}$ emission cost is in order of asphalt, membrane, and sheet waterproofing, whereas the cost for $\mathrm{CO}_{2}$ emission of each method is in a different order: membrane, asphalt, and sheet waterproofing. Despite the different $\mathrm{CO}_{2}$ emission costs, the order of total cost for each method does not change, as the $\mathrm{CO}_{2}$ emission cost required in the initial stage accounts for a relatively small portion of the total cost. Therefore, the total cost considering the $\mathrm{CO}_{2}$ emission cost is almost the same as that without considering it.

Table 13. Cost for construction and $\mathrm{CO}_{2}$ emission at initial stage.

\begin{tabular}{lccc}
\hline \multicolumn{1}{c}{ System } & Initial construction cost & Initial CO $\mathbf{C O}_{2}$ emission cost & Sum \\
\hline Asphalt waterproofing & 44,319 & 1062.7 & 45,382 \\
Membrane waterproofing & 41,538 & 1741.9 & 43,280 \\
Sheet waterproofing & 31,616 & 924.4 & 32,541 \\
\hline
\end{tabular}

\subsection{Maintenance and Repair Cost}

In LCC analysis, cost factors identified by CBS are continuously generated over the lifecycle of a building. All cost factors in CBS are discounted to their equivalent present values based on the relevant discount factors as part of LCC procedure. In addition, the time-based milestones should be obvious. Tables 14 and 15 represent the cost of maintenance and repair in current prices and the net present value by the number of years.

Table 14. Accumulated operation and maintenance cost $\left(\mathrm{LCCO}_{2} \operatorname{cost}\right.$ excluded).

\begin{tabular}{|c|c|c|c|c|c|c|}
\hline \multirow{2}{*}{ Year } & \multicolumn{2}{|c|}{ Asphalt waterproofing } & \multicolumn{2}{|c|}{ Membrane waterproofing } & \multicolumn{2}{|c|}{ Sheet waterproofing } \\
\hline & Current price & Present value & Current price & Present value & Current price & Present value \\
\hline 5 & & & 6592 & 5714 & & \\
\hline 8 & 6871 & 5466 & & & 11,200 & 8911 \\
\hline 10 & & & 13,185 & 10,668 & & \\
\hline 15 & & & 79,109 & 53,603 & & \\
\hline 16 & 13,741 & 9815 & & & 22,401 & 16,000 \\
\hline 20 & & & 85,701 & 57,325 & & \\
\hline 24 & 82,447 & 44,410 & & & 78,403 & 47,615 \\
\hline 25 & & & 92,294 & 60,550 & & \\
\hline 28 & & & & & 89,603 & 52,645 \\
\hline 30 & & & 158,218 & 88,513 & & \\
\hline 32 & 89,317 & 47,163 & & & & \\
\hline 35 & & & 164,810 & 90,937 & & \\
\hline
\end{tabular}


Table 14. Cont.

\begin{tabular}{ccccccccc}
\hline \multirow{2}{*}{ Year } & \multicolumn{2}{c}{ Asphalt waterproofing } & & \multicolumn{2}{c}{ Membrane waterproofing } & & \multicolumn{2}{c}{ Sheet waterproofing } \\
\cline { 2 - 3 } & Current price & Present value & & Current price & Present value & & Current price & Present value \\
\hline 36 & & & & & & & 100,804 & 56,647 \\
\hline 40 & 96,188 & 49,352 & 171,403 & 93,038 & & 156,806 & 75,495 \\
\hline 44 & & & & & & 168,006 & 77,679 \\
\hline 45 & 103,058 & 51,250 & 237,327 & 111,250 & & \\
\hline Repair & 34,593 & 16,655 & 39,554 & 22,140 & & 56,002 & 28,216 \\
\hline Replacement & 68,705 & 34,596 & 197,772 & 89,110 & & 112,004 & 49,463 \\
\hline
\end{tabular}

Table 15. Accumulated operation and maintenance cost $\left(\mathrm{LCCO}_{2}\right.$ cost included).

\begin{tabular}{|c|c|c|c|c|c|c|}
\hline \multirow{2}{*}{ Year } & \multicolumn{2}{|c|}{ Asphalt waterproofing } & \multicolumn{2}{|c|}{ Sheet waterproofing } & \multicolumn{2}{|c|}{ Membrane waterproofing } \\
\hline & Current price & Present value & Current price & Present value & Current price & Present value \\
\hline 5 & & & & & 6838 & 5927 \\
\hline 8 & 7222 & 5746 & 11,876 & 9448 & & \\
\hline 10 & & & & & 13,675 & 11,065 \\
\hline 15 & & & & & 83,794 & 56,732 \\
\hline 16 & 1444 & 10,317 & 23,752 & 16,965 & & \\
\hline 20 & & & & & 90,632 & 60,592 \\
\hline 24 & 8666 & 46,683 & 83,131 & 46,864 & & \\
\hline 25 & & & & & 97,470 & 63,938 \\
\hline 28 & & & 96,007 & 52,198 & & \\
\hline 30 & & & & & 167,589 & 93,689 \\
\hline 32 & 93,887 & 49,576 & & & & \\
\hline 35 & & & & & 174,426 & 96,194 \\
\hline 36 & & & 106,883 & 56,441 & & \\
\hline 40 & 101,109 & 51,878 & 166,262 & 75,366 & 181,264 & 98,272 \\
\hline 44 & & & 178,138 & 78,742 & & \\
\hline 45 & 108,332 & 53,873 & & & 251,383 & 117,744 \\
\hline Repair & 36,111 & 17,507 & 59,379 & 29,918 & 41,026 & 22,964 \\
\hline Replacement & 72,221 & 36,366 & 118,759 & 48,824 & 210,357 & 94,780 \\
\hline
\end{tabular}

In Table 16, four factors of maintenance and repair are compared with; the initial investment cost and; repair cost; replacement cost. The results show that the initial cost for asphalt is demanded, whereas the repair and replacement cost of membrane waterproofing are higher than those in other methods.

Table 16. Analysis of maintenance cost.

\begin{tabular}{cccccc}
\hline System & Initial construction costs & Repair cost & Replacement cost & Cost for O\&M & Total \\
\hline Asphalt waterproofing & 45,382 & 17,507 & 36,366 & 53,873 & 99,255 \\
Membrane waterproofing & 43,280 & 22,964 & 94,780 & 117,744 & 161,024 \\
Sheet waterproofing & 32,541 & 29,824 & 48,824 & 78,648 & 111,189 \\
\hline
\end{tabular}




\subsection{LCC Comparison Including $\mathrm{LCCO}_{2}$}

Regardless of its high initial capital cost, the asphalt waterproofing method is the most economic method for a lifetime of 45 years. In contrast, the total cost of sheet waterproofing is highest despite having the lowest initial investment. This implies that $\mathrm{LCCO}_{2}$ can influence the total construction cost and should be considered for economic construction. In addition, $\mathrm{LCCO}_{2}$ can greatly influence the total cost, depending on structure lifetime, despite the fact that $\mathrm{LCCO}_{2}$ accounts for only a small part of LCC. This can be evidenced by the changed ratio of $\mathrm{LCCO}_{2}$ as shown in Table 17. The asphalt waterproofing LCC ratio compared with the LCC of membrane system is increased by $1 \%$ when the $\mathrm{CO}_{2}$ emission cost is considered while the LCC cost ratio of sheet system shows the three times increase.

Table 17. LCC ratio comparison.

\begin{tabular}{cccc}
\hline & Asphalt & Membrane & Sheet \\
\hline LCC & $31,901.95$ & $52,306.02$ & $46,851.83$ \\
Ratio (\%) & 61 & 100 & 90 \\
LCC + LCCO2 & $33,222.68$ & $53,514.41$ & $49,511.74$ \\
Ratio (\%) & 62 & 100 & 93 \\
\hline
\end{tabular}

\section{Conclusions}

This study proposes LCC analysis for integrating the economic aspect with the environmental aspect by integrating the $\mathrm{LCCO}_{2}$ of each waterproofing method into the LCC. The waterproofing methods selected for this research are sheet, asphalt, and membrane waterproofing. The costs for these three methods over their lifetimes are analyzed and $\mathrm{LCC}$ and $\mathrm{LCCO}_{2}$ are calculated. The following conclusions are drawn about the major drivers of this research:

(1) In terms of initial capital cost, asphalt waterproofing has the highest $\mathrm{CO}_{2}$ emission cost, followed by membrane and sheet waterproofing. However, $\mathrm{LCC}$ including $\mathrm{LCCO}_{2}$ suggests that membrane waterproofing requires the highest cost, followed by sheet and asphalt waterproofing. In terms of initial capital cost, sheet waterproofing can be competitive, but it is expensive in the maintenance and repair stage. Asphalt waterproofing, however, has a high initial cost and low maintenance cost. Therefore, asphalt waterproofing can be the most economic method given that the $\mathrm{LCCO}_{2}$ is considered in LCC.

(2) The LCC for each method including $\mathrm{LCCO}_{2}$ has resulted in a valid economic perspective, i.e., although the initial cost for sheet waterproofing is the lowest, asphalt waterproofing is more economical based on LCC analysis.

(3) $\mathrm{LCCO}_{2}$ is a relatively small portion of LCC, and at a glance, may have little influence on the construction and maintenance costs. However, the length of LCC or durability of a building increases the $\mathrm{LCCO}_{2}$, and can accumulate into an amount that could have an economic impact on decision-making. Therefore, it can be concluded that $\mathrm{LCCO}_{2}$ can be a vital factors in the process.

In this research, LCC analysis of roof waterproofing methods is proposed for a new building or refurbishment of existing buildings. The analysis framework can be adopted for different construction methods and structures. In addition, it can be considered for various industries and other construction 
projects for decision-making in the initial planning and design stage. The research process implies that cost calculation in the initial and maintenance stages is reasonably reliable owing to the detailed $\mathrm{CO}_{2}$ emission basic unit data in input-output tables. However, the data in the tables has limited use in the demolition stage. As a basic unit database for that stage is not available, historical data is used in this study. Therefore, further studies may have higher reliability and objectivity provided that the data relevant to the disposal and demolition stage can be used as basic unit data.

\section{Conflicts of Interest}

The authors declare no conflict of interest.

\section{References}

1. Project Management Institute (PMI). Guide to the Project Management Body of Knowledge; PMI: Newtown Square, PA, USA, 2004.

2. Khasreen, M.M.; Banfill, P.F.G.; Menzies, G.F. Life-cycle assessment and the environmental impact of buildings: A review. Sustainability 2009, 1, 674-701.

3. Lawrence, T.M.; Braun, J.E. Evaluation of simplified models for predicting $\mathrm{CO}_{2}$ concentrations in small commercial buildings. Build. Environ. 2006, 41, 184-194.

4. Radhi, H. Evaluating the potential impact of global warming on the UAE residential buildings - a contribution to reduce the $\mathrm{CO}_{2}$ emissions. Build. Environ. 2009, 44, 2451-2462.

5. Oh, S.K.; Bae, K.S.; Kim, Y.S. A study on the evaluation of composite coatings of cement and powder used as waste tire and glass. Archit. Inst. Korea 2004, 20, 47-52.

6. Kang, C.H.; Kim, Y.S. The current status and case studies on the waterproofing defects in the underground parking lot of apartment buildings. Proc. Archit. Inst. Korea 2001, 21, 503-506.

7. An, G.U.; Lee, J.Y. Defection analysis of the waterproof work for the quality control of construction site. Archit. Inst. Korea 2005, 21, 123-130.

8. Oh, S.K.; Kwak, K.S.; Choi, S.M.; Kwan, S.W. Improvement of selection system of waterproofing methods for concrete structure. Korea Inst. Build. Constr. 2007, 7, 99-106.

9. Dale, A.T.; Lucena, A.F.P.; Marriott, J.; Borba, B.S.M.C.; Schaeffer, R.; Bilec, M.M. Modeling future life-cycle greenhouse gas emissions and environmental impacts of electricity supplies in Brazil. Energies 2013, 6, 3182-3208.

10. Choi, O.Y.; Kim, T.; Kim, G. A study on selection of roof waterproofing method by analyzing life cycle costing. Korea Inst. Build. Constr. 2008, 1, 127-134.

11. Choi, S.M.; Oh, S.K.; Seo, C.H. A study on the selection of the waterproofing methods which VE/RWLCC analysis methodology in roof of structure. Archit. Inst. Korea 2009, 25, 161-168.

12. Wang, C.; Zhang, L.; Yang, S.; Pang, M. A hybrid life-cycle assessment of non-renewable energy and greenhouse-gas emissions of a village-level biomass gasification project in China. Energies 2012, 5, 2708-2723.

13. Promjiraprawat, K.; Limmeechokchai, B. Assessment of Thailand's energy policies and $\mathrm{CO}_{2}$ emissions: Analyses of energy efficiency measures and renewable power generation. Energies 2012, 5, 925-937. 
14. Kim, J.Y.; Lee, S.E.; Sohn, J.Y. An assessment of the energy consumption \& $\mathrm{CO}_{2}$ emission during the construction stage of apartments. Archit. Inst. Korea 2005, 21, 199-206.

15. Gao, L.; Winfield, Z.C. Life cycle assessment of environmental and economic impacts of advanced vehicles. Energies 2012, 5, 605-620.

16. Lee, B.Y.; Kim, B.R.; Kim, G.H. Comparison of construction costs of masonry wall types, including $\mathrm{CO}_{2}$ emission costs. Korea Inst. Build. Constr. 2010, 10, 83-90.

17. KICT. Life cycle analysis annual report. Available online: http://www.kict.re.kr/ (accessed on 27 September 2013).

18. Jung, S.S.; Kim, D.W. A study on the development of cost breakdown structure in present worth method and annul worth method by HAVC system for systematic LCC calculation. Archit. Inst. Korea 2002, 18, 167-174.

19. Son, B.S.; Jang, M.H.; Lee, H.Y. A method of economic analysis for remodelling of apartments using the life cycle costing. Archit. Inst. Korea 2005, 21, 73-81.

20. Choi, M.S.; Kim, M.H. The variation characteristics of life cycle cost in a office building according to the discount rates and inflation rates. Archit. Inst. Korea 2006, 22, 131-137.

(C) 2013 by the authors; licensee MDPI, Basel, Switzerland. This article is an open access article distributed under the terms and conditions of the Creative Commons Attribution license (http://creativecommons.org/licenses/by/3.0/). 